\title{
One year of the COVID-19 pandemic in Poland-the incidence of osteoporotic forearm, arm, and hip fractures
}

\author{
Robert Wilk ${ }^{1} \cdot$ Piotr AdamCzyk ${ }^{2} \cdot$ Wojciech Pluskiewicz ${ }^{3} \cdot$ Michał Skrzypek $^{4} \cdot$ Marcin Hajzyk $^{5} \cdot$ Bogdan Koczy $^{6}$
}

Received: 8 November 2021 / Accepted: 23 February 2022 / Published online: 3 March 2022

(c) International Osteoporosis Foundation and National Osteoporosis Foundation 2022

\begin{abstract}
Summary The study attempts to analyse whether the COVID-19 pandemic affected the incidence of forearm, arm, and hip fractures during a 1-year observation period. Additionally, changes in the overall treatment costs of those fractures were estimated. During the COVID-19 pandemic, the incidence of forearm, arm, and hip fractures remained statistically unchanged, neither were any significant changes observed in the expenditure, incurred for the treatment of the fracture cases.

Purpose The purpose of the study was to find out and evaluate if the consequences of COVID-19 pandemic (including lockdown and the fear of infection) influenced the incidence of osteoporotic forearm, arm, and hip fractures and to estimate the changes in the costs of their management during one-year observation period.

Methods The incidence of forearm, arm, and hip fractures was collected for the population, aged $\geq 50$, residing at the district of Tarnowskie Góry and the Town of Piekary Śląskie, Poland, during 1 year of COVID-19 pandemic (from March 16th 2020 to March 15th 2021). The obtained results were compared with the number of corresponding limb fractures, recorded before the pandemic during five consecutive yearly periods, each starting from 16th March and ending on the 15th March of a subsequent year, the entire period covering the years 2015-2020. The rates of the analysed fractures were calculated per 100,000 inhabitants together with their economic impact.

Results The mean numbers and the incidence rates of upper extremity fractures were slightly lower during the COVID-19 pandemic than in the previous 5 years, whereas hip fracture figures remained almost stable. The observed changes were not statistically significant. That annual observation revealed a slight decrease in expenditure volumes, when compared to the analysed period before the pandemic $(-0.33 \%)$.

Conclusion The decreased incidence rate of forearm, arm, and hip fractures, observed during the first months of the COVID-19 pandemic, was not statistically significant in the 1-year observation. After several weeks/months under the shock, caused by government limitations and the fear of infection, the number of patients remained unchanged during the one-year observation.
\end{abstract}

Keywords Fracture $\cdot$ COVID-19 pandemic $\cdot$ Forearm $\cdot$ Arm $\cdot$ Hip

Robert Wilk

drrobertwilk@gmail.com

1 Department of Orthopedic and Trauma Surgery, Municipal Hospital (Sosnowiecki Szpital Miejski), ul. Emila Zegadłowicza 3, 41-200 Sosnowiec, woj. śląskie, Poland

2 Department of Pediatrics, Faculty of Medical Sciences in Katowice, Medical University of Silesia, Katowice, Poland

3 Department and Clinic of Internal Diseases, Diabetology, and Nephrology, Metabolic Bone Diseases Unit, Faculty of Medical Sciences in Zabrze, Medical University of Silesia, Katowice, Poland

4 Department of Biostatistics, School of Public Health in Bytom, Medical University of Silesia in Katowice, Bytom, Poland

5 Department of Pediatric Orthopedics \& Traumatology, Combined City Hospitals, Chorzów, Poland

6 Department of Trauma and Orthopedics, District Hospital of Orthopedics and Trauma Surgery, Piekary Śląskie, Poland 


\section{Introduction}

The COVID-19 outbreak that began in China has infected millions of people worldwide [1]. The first patient in Poland, infected with SARS-CoV-2, was officially diagnosed on 4th March 2020 [2]. On the 11th March 2020, The World Health Organization (WHO) declared that the global crisis over the new coronavirus was a pandemic [3]. Before the declaration of the pandemic in our country (20th March 2020), very worrisome reports were published in Italy [4]. The first lockdown procedure in Poland was announced on the 16th of March [5]. It was the first official restriction, imposed on human migration and meetings. TV programs and websites all over the world brought streams of information about dangers, associated with SARS-CoV-2 infection, influencing populations' behaviours [6], as the raised fear of COVID-19 infection became really huge [7]. Because of government restrictions (lockdowns, quarantines) and COVID-19-phobia, people locked themselves at their houses, avoiding going outdoors as much as possible and stayed at home even if they needed medical consultation. The COVID-19 pandemic has had a marked impact on societies around the world. Patients did not arrive at hospitals or call ambulance services even for cardiological or surgical reasons $[8,9]$. That situation affects both adults and children [8-11]. These circumstances refer also to patients after a fall from a standing position [10]. Considering the most common osteoporotic fractures, the situation looks similar [12]. In case of upper extremity fractures, people suffer from pain for several weeks but, afterwards, they usually recover achieving almost their normal fitness $[13,14]$. The situation is different after hip injury (femoral neck or per/subtrochanteric fractures), which is the most challenging type of fracture both for affected patients and their families, due to the patient's inability to carry out daily activities-patients remain in bed for many weeks suffer from severe pain and symptoms related to blood loss. Furthermore, the cumulative mortality rate for the 12 months is about $30 \%$ [15].

Regarding our previous report, analysing the early pandemic period, we observed decreased fracture incidence rates in Poland at each analysed location, i.e. the forearm, the arm and the hip [16]. We collected the data for the first weeks of the COVID-19 pandemic when a very strict 'lockdown' strategy was introduced (the first 77 days, from 16th March to 31 st May 2020). Currently, we extended the observation period to one year. The aims of our study remain unchanged. The longer observation period should give a wider data with a more accurate analysis of the pandemic impact on possible changes in people's behaviour. Numbers of patients with lowenergy fractures at emergency departments may be linked to these behaviour changes.
The primary aim of this study was to evaluate the impact of the pandemic restrictions and the fear of the SARS-CoV-2 virus on the number of patients at the emergency department with osteoporotic fractures, mainly of the forearm, arm and hip.

The secondary aim was to analyse the influence of fracture rate changes on the expenditure pattern for the Polish health care system [17].

\section{Methods}

The incidence of low-energy forearm, arm and hip fractures, defined as a result of falling from a standing height or less, were collected for the population aged $\geq 50$ years, at the district of Tarnowskie Gory and the Town of Piekary Śląskie (both are in Upper Silesia Region at the South of Poland), during the first year of COVID-19 pandemic, when the 'lockdown' strategy was periodically introduced-from 16th March 2020 to 15th March 2021. The study area comprised both urban and rural settlements. The fractures were identified according to ICD-10 classification (appropriate subtypes of S42, S52, and S72 codes) from medical records at the Trauma Surgery Hospital in Piekary Śląskie-the only orthopaedic surgery hospital in that area. Each fracture was diagnosed by X-ray. Additionally, V00- Y99 ICD-10 codes, which describe the external causes of morbidity, were analysed to identify and exclude all high-energy fractures from the study. For comparisons with previous years, the numbers of forearm, arm and hip fractures were also collected for the five consecutive yearly periods between years 2015-2020, where each year of observation started from 16th March and ended on the 15th March of a subsequent year. Then, the rates of analysed fractures were calculated per 100,000 of the population, aged $\geq 50$ years, with a $95 \%$ confidence interval, based on the number of inhabitants at this age category in the whole district. In consecutive years for period 2015-2020, there were 75,567, 76,194, 76,740, 77,151, 77,744 , and 78,129 residents, respectively [18]. Incidence rate ratios of fractures rates before the pandemic and during the pandemic period were calculated based on the Poisson regression model. In order to estimate a potential impact of changes in the fracture incidence rates during the COVID-19 pandemic on the Polish healthcare system, the costs of individual patient management were taken into account and the financial data were sourced from the Polish National Health Service report, published in November 2019 [17]. The costs of medical care for an individual case of forearm, arm or hip fracture, expressed in Euro, were $€ 215, € 330$ and $€ 1720$, respectively. The mean total annual number of osteoporotic forearm, arm and hip fractures was then calculated for the whole country of Poland, based on the above-mentioned 
Table 1 The number and incidence rates of fractures before and during the COVID-19 pandemic in the studied area

\begin{tabular}{llllll}
\hline Location & $\begin{array}{l}\text { The mean number of } \\
\text { fractures before the } \\
\text { pandemic }\end{array}$ & $\begin{array}{l}\text { The number of } \\
\text { fractures during the } \\
\text { pandemic }\end{array}$ & $\begin{array}{l}\text { The mean incidence rate } \\
\text { before the pandemic } \\
\text { (n/100000 with 95\% } \\
\text { confidence interval) }\end{array}$ & $\begin{array}{l}\text { The incidence rate } \\
\text { during the pandemic } \\
(\mathrm{n} / 100000 \text { with } 95 \% \\
\text { confidence interval) }\end{array}$ & $\begin{array}{l}\text { IRR with 95\% } \\
\text { confidence interval }\end{array}$ \\
\hline Forearm & $270.0 \pm 36.5$ & 225 & $352.1(311.4-396.7)$ & $288.0(251.6-328.2)$ & 0.82 (95\% CI: 0.60-1.09) 0.19 \\
Arm & $141.4 \pm 14.2$ & 122 & $183.9(154.8-216.9)$ & $156.2(129.7-186.4)$ & 0.85 (95\% CI: 0.65-1.08) 0.20 \\
Hip & $173.2 \pm 9.1$ & 182 & $225.6(193.3-261.9)$ & $232.9(200.3-269.4)$ & 1.03 (95\% CI: 0.93-1.14) 0.56
\end{tabular}

$I R R$ incidence rate ratio

rates. In order to estimate changes in costs of medical services for fractures treatment, provided during the pandemic period, the mean numbers of fractures for observing periods in the years 2015-2020 and the number of fractures in the current period of observation were multiplied by the medical care costs for each fracture site. All the results are presented for males and females together.

\section{Results}

The numbers of forearm, arm and hip fractures during the first year of the COVID-19 pandemic in the analysed region were 225,122 and 182 . The mean numbers and incidence rates of upper extremity fractures during the COVID-19 pandemic were slightly lower than during the 5 previous years, whereas, the number of hip fractures remained almost stable. The differences were not statistically significant at any fracture location (Table 1).

The numbers of fractures and their treatment costs, estimated for the whole country in a period of five consecutive years 2015-2019 and in the current 365-day period of observation during the pandemic time are presented in Table 2. The estimated numbers of sustained forearm, arm, and hip fractures, adjusted for the whole country in the pandemic period were $41,486,22,472$, and 33,564 . The total annual number of fractures at the analysed skeletal sites was for $10,451(9.68 \%)$ lower than before the pandemic.
The expected nationwide reduction of expenditure for the forearm and arm fracture treatment was estimated for $17.04 \%$ and $15.67 \%$. However, the costs of hip fracture treatment increased by $5 \%$, compared to the time before the COVID-19 pandemic. In general, the entire costs of fractures treatment decreased for $0.33 \%$ only (Table 2).

\section{Discussion}

In relation to analysed low-energy fractures of the upper extremity, the decrease of the incidence rate of forearm fractures was the most noticeable during the pandemic period, similar to other countries [19-21]. Regarding the results of the other study, the same situation was observed in other Polish regions [22], but this study reported the results just for 7 months (from March 15th to October 15th, 2020) only and the period of observation did not cover the winter season with an expected increase in fracture incidence. The trend of a low forearm fracture number during the pandemic could be due to the following three causes: firstly, people had to stay at home due to lockdown restrictions or quarantines, whereas, according to literature, the most common mechanism of forearm fracture is falling while walking outside [23]; secondly, there was the fear of catching COVID-19 infection at the hospital; thirdly, there were transport problems to hospital during quarantines and injury symptoms were reduced after the quarantine expires and the refusal

Table 2 The number of fractures in the whole country and the costs of their treatment

\begin{tabular}{|c|c|c|c|c|c|c|}
\hline Location & $\begin{array}{l}\text { 'Background' mean } \\
\text { annual number } \\
\text { of fractures in } \\
2015-2019 \text { years }\end{array}$ & $\begin{array}{l}\text { The number of } \\
\text { fractures during } \\
\text { the pandemic year } \\
(2020 / 2021)\end{array}$ & $\begin{array}{l}\text { The costs of } \\
\text { treatment of indi- } \\
\text { vidual fracture in } \\
\text { Poland (euro) }\end{array}$ & $\begin{array}{l}\text { The mean annual } \\
\text { cost of treatment } \\
\text { before the pandemic } \\
\text { (euro) }\end{array}$ & $\begin{array}{l}\text { The cost of treatment } \\
\text { during the pandemic } \\
\text { (euro) }\end{array}$ & Difference (euro) \\
\hline Forearm & 50008 & 41486 & 215 & 10751720 & 8919490 & $\begin{array}{l}-1832230 \\
(-17.04 \%)\end{array}$ \\
\hline Arm & 25999 & 22472 & 330 & 8579670 & 7415760 & $\begin{array}{l}-1163910 \\
(-13.57 \%)\end{array}$ \\
\hline Hip & 31966 & 33564 & 1720 & 54981520 & 57730080 & $\begin{array}{l}+2748560 \\
(+5.00 \%)\end{array}$ \\
\hline Total & 107973 & 97522 & $\operatorname{xxxx}$ & 74312910 & 74065330 & $\begin{array}{l}-247580 \\
(-0.33 \%)\end{array}$ \\
\hline
\end{tabular}


of elderly patients to participate in diagnostic procedures, regarding suspected fractures.

The incidence rate of humeral fractures was also lower but that decrease was less pronounced. As described in the literature, the epidemiology of humeral fractures is still unclear. Some studies refer that the majority of the fractures result from falls on the floor at home, while other studies refer that humeral fractures take place mostly in winter months, suggesting a higher incidence of outdoor falls $[24,25]$. Our results confirmed the thesis that staying at home reduces the number of humeral fractures. However, we could not exclude the impact of the problems described above (COVID-19 phobia and quarantine-related issues). A similar situation of less humeral fractures was also described in Italian and British hospitals [26, 27].

It is quite different in the case of hip fractures, where the imposed circumstances, including the immediate inability for personal care, as the affected patient is bedridden and suffering, are far from inducing the patient's refusal to admit the emergency department and orthopaedic ward. At the beginning of the pandemic, we observed a decrease in the number of patients with hip injury [16]. However, the situation changed during the entire year of observation. Many families used to call the ambulance after a fall due to the patient's immediate walking inability. Furthermore, the most common mechanism of injury was indoor falling, thus, according to results from our study, there could be considered that lockdown had not affected the overall hip fracture rate [28]. Then, it is also necessary to take into account greater care for the elderly because families either did not need to go to work or worked at home. According to worldwide literature reports, the impact of the COVID-19 pandemic on the number of patients with hip fractures was different. A decrease in hip fracture incidence was observed in India, Hong Kong and in one region of Spain but in those studies, the period of observation was only two months maximum [20, 29, 30]. In another Spanish region, the number of osteoporotic hip fractures remained stable throughout the observation period, except of only the first 20 days of the pandemic [31]. British observations confirmed that estimation [32].

Economically, the COVID-19 pandemic did not affect the financial funding of osteoporotic fracture treatment. The annual observation shows a slight decrease in the expenditure, compared to the period before the pandemic $(-0.33 \%)$. However, considering the annual increase of elderly population rate in Poland [33], which increases the total costs of theirs medical treatment, even a slight decrease in expenditure seems to be remarkable.

Our study has several limitations. We studied a population of one region of Poland only and the extrapolation of the results for the whole country to estimate the number of fractures and the costs of their treatment may not be relevant to the whole country. Due to the relatively small number of fractures, no separate studies were undertaken for females and males. We also did not collect data on the trends in the use of anti-resorptive therapy or vitamin D supplementation over the prior years or on any other confounding factors that could have impacted the fracture risk in the current year, what could be considered as a limitation of the study. We did not estimate the number of spine fractures because of poor clinical symptoms and no fall history in most cases and possible bias consequently [34].

Concluding, the substantial decrease in the incidence rates of forearm and arm fractures, observed during the first months of the COVID-19 pandemic, was not statistically significant during the one-year observation. The studied patients, after several weeks/months of shock, caused by governmental restrictions and the fear of infection, did not reveal any changes during the one-year observation. The number of hip fractures in our region also remained stable during the pandemic period in comparison to previous years [28]. The decrease in treatment costs, which was confirmed by observations of the early pandemic period with a strict-lockdown-strategy, became almost negligible during the whole year observation. There could be summarised that the outbreak of the pandemic caused only shortterm changes in the incidence of the forearm, arm and hip fractures, with subsequent 'rebound' phenomena after the release of pandemic strategy.

\section{Declarations}

Conflict of interest None.

\section{References}

1. Zhu N, Zhang D, Wang W et al (2020) China Novel Coronavirus Investigating and Research Team. A novel coronavirus from patients with pneumonia in China 2019. N Engl J Med 382:727733. https://doi.org/10.1056/NEJMoa2001017

2. Raciborski F, Pinkas J, Jankowski M et al (2020) Dynamics of the coronavirus disease 2019 outbreak in Poland: an epidemiological analysis of the first 2 months of the epidemic. Pol Arch Intern Med 130(7-8):615-621. https://doi.org/10.20452/pamw.15430

3. Cucinotta D, Vanelli M (2020) WHO Declares COVID-19 a Pandemic. Acta Biomed 91(1):157-160. https://doi.org/10.23750/ abm.v91i1.9397

4. Rothan HA, Byrareddy SN (2020) The epidemiology and pathogenesis of coronavirus disease (COVID-19) outbreak. J Autoimmun 109:102433. https://doi.org/10.1016/j.jaut.2020.102433

5. Szczurek-Żelazko J (2020) Regulation of the Minister of Health from 16th March 2020 https://isap.sejm.gov.pl/isap.nsf/DocDe tails.xsp?id=WDU20200000461. Accessed 9 Sept 2021

6. Torales J, O'Higgins M, Castaldelli-Maia JM, Ventriglio A (2020) The outbreak of COVID-19 coronavirus and its impact on global mental health. Int J Soc Psychiatry 66(4):317-320. https://doi.org/ $10.1177 / 0020764020915212$ 
7. Fofana N, Latif F, Sarfraz S et al (2020) Fear and agony of the pandemic leading to stress and mental illness: An emerging crisis in the novel coronavirus (COVID-19) outbreak. Psychiatry Res 291:113230. https://doi.org/10.1016/j.psychres.2020.113230

8. Leyva F, Zegard A, Okafor O et al (2021) Cardiac operations and interventions during the COVID-19 pandemic: a nationwide perspective. Europace 23(6):928-936. https://doi.org/10.1093/europ ace/euab013

9. Kurihara H, Marrano E, Ceolin M et al (2021) Impact of lockdown on emergency general surgery during first 2020 COVID-19 outbreak. Eur J Trauma Emerg Surg 47(3):677-682. https://doi.org/ 10.1007/s00068-021-01691-3

10. Greenhalgh M, Dupley L, Unsworth R, Boden R (2021) Where did all the trauma go? A rapid review of the demands on orthopaedic services at a UK Major Trauma Centre during the COVID-19 pandemic. Int J Clin Pract 75(3):e13690. https://doi.org/10.1111/ ijcp. 13690

11. Bram J, Johnson M, Magee L et al (2020) Where Have All the Fractures Gone? The Epidemiology of Pediatric Fractures During the COVID-19 Pandemic. J Pediatr Orthop 40(8):373-379. https:// doi.org/10.1097/BPO.0000000000001600

12. Hernlund $\mathrm{E}$, Svedbom $\mathrm{A}$, Ivergård $\mathrm{M}$ et al (2013) Osteoporosis in the European Union: medical management, epidemiology and economic burden. A report prepared in collaboration with the International Osteoporosis Foundation (IOF) and the European Federation of Pharmaceutical Industry Associations (EFPIA). Arch Osteoporos 8(1):136. https://doi.org/10.1007/ s11657-013-0136-1

13. Hassellund S, Williksen J, Laane M et al (2021) Cast immobilization is non-inferior to volar locking plates in relation to QuickDASH after one year in patients aged 65 years and older: a randomized controlled trial of displaced distal radius fractures. Bone Joint J 103(2):247-255. https://doi.org/10.1302/0301-620X. 103B2.BJJ-2020-0192.R2

14. Beks R, Ochen Y, Frima $\mathrm{H}$ et al (2018) Operative versus nonoperative treatment of proximal humeral fractures: a systematic review, meta-analysis, and comparison of observational studies and randomized controlled trials. J Shoulder Elbow Surg 27(8):1526-1534. https://doi.org/10.1016/j.jse.2018.03.009

15. Guzon-Illescas O, Fernandez E, Villarias N et al (2019) Mortality after osteoporotic hip fracture: incidence, trends, and associated factors. J Orthop Surg Res 14(1):203. https://doi.org/10.1186/ s13018-019-1226-6

16. Pluskiewicz W, Wilk R, Adamczyk P et al (2021) The incidence of arm, forearm, and hip osteoporotic fractures during early stage of COVID-19 pandemic. Osteoporos Int 32(8):1595-1599. https:// doi.org/10.1007/s00198-020-05811-4

17. National Health Service on Health. Osteoporosis. (In Polish).Warsaw, November 2019

18. Statistics Poland (2021) Bank Danych Lokalnych, Warsaw. https:// bdl.stat.gov.pl. Accessed 9 Sept 2021

19. Poggetti A, Del Chiaro A, Nucci A et al (2020) How hand and wrist trauma has changed during covid-19 emergency in Italy: Incidence and distribution of acute injuries: What to learn? J Clin Orthop Trauma 12(1):22-26. https://doi.org/10.1016/j.jcot.2020. 08.008

20. Reddy M, Mulpur P, Guravareddy A et al (2020) Impact of COVID-19 Pandemic on Orthopaedic Trauma Volumes: a MultiCentre Perspective From the State of Telangana. Indian J Orthop 54(Suppl 2):1-6. https://doi.org/10.1007/s43465-020-00226-Z
21. Mitkovic M, Bumbasirevic M, Milenkovic S et al (2021) Influence of coronavirus disease 2019 pandemic state of emergency in orthopaedic fracture surgical treatment. Int Orthop 45(4):815820. https://doi.org/10.1007/s00264-020-04750-3

22. Olech J, Ciszewski M, Morasiewicz P (2021) Epidemiology of distal radius fractures in children and adults during the COVID19 pandemic - a two-center study. BMC Musculoskelet Disord 22(1):306. https://doi.org/10.1186/s12891-021-04128-5

23. Solvang H, Nordheggen R, Clementsen $S$ et al (2018) Epidemiology of distal radius fracture in Akershus Norway in 2010 2011. J Orthop Surg Res 13(1):199. https://doi.org/10.1186/ s13018-018-0904-0

24. Lind T, Krøner K, Jensen J (1989) The epidemiology of fractures of the proximal humerus. Arch Orthop Trauma Surg 108(5):285287. https://doi.org/10.1007/BF00932316

25. Launonen AP, Lepola V, Saranko A et al (2015) Epidemiology of proximal humerus fractures. Arch Osteoporos 10:209. https://doi. org/10.1007/s11657-015-0209-4

26. Maniscalco P, Ciatti C, Gattoni S et al (2021) Proximal humerus fractures in COVID-19 lockdown: the experience of three orthopedics and traumatology departments in the first ten weeks of the Italian epidemic. Acta Biomed 92(1):e2021104. https://doi.org/ 10.23750/abm.v92i1.11231

27. Ogliardi G, Lunt E, Ong T et al (2020) The impact of lockdown during COVID-19 pandemic on osteoporotic fracture fragility: an observational study. Arch Osteoporos 15:156. https://doi.org/10. 1007/s11657-020-00825-1

28. Wilk R, Skrzypek M, Kowalska M et al (2018) The 13-year observation of hip fracture in Poland-worrying trend and prognosis for the future. Aging Clin Exp Res 30(1):61-69. https://doi.org/10. 1007/s40520-017-0747-2

29. Minarro J, Zamorano-Moyano C, Urbano-Luque M et al (2020) Is COVID-19 affecting the incidence of hip fractures? Injury 51(10):2329. https://doi.org/10.1016/j.injury.2020.07.018

30. Wong J, Cheung K (2020) Impact of COVID-19 on Orthopaedic and Trauma Service: An Epidemiological Study. J Bone Joint Surg Am 102(14):e80. https://doi.org/10.2106/JBJS.20.00775

31. Nuñez J, Sallent A, Lakhani K et al (2020) Impact of the COVID19 Pandemic on an Emergency Traumatology Service: Experience at a Tertiary Trauma Centre in Spain. Injury 51(7):1414-1418. https://doi.org/10.1016/j.injury.2020.05.016

32. Ogliardi G, Lunt E, Ong T, Marshall L, Sahota O (2020) The impact of lockdown during COVID-19 pandemic on osteoporotic fracture fragility: an observational study. Arch Osteoporos 15:156. https://doi.org/10.1007/s11657-020-00825-1

33. Wilk R, Skrzypek M, Kowalska M et al (2017) Do we need orthogeriatrics in Poland? Changes in the age structure and location of hip fractures. Aging Clin Exp Res 29(4):737-743. https://doi.org/ 10.1007/s40520-016-0627-1

34. McCarthy J, Davis A (2016) Diagnosis and Management of Vertebral Compression Fractures. Am Fam Physician 94(1):44-50 (PMID: 27386723)

Publisher's Note Springer Nature remains neutral with regard to jurisdictional claims in published maps and institutional affiliations. 